\title{
VIROTERAPIA ONCOLÍTICA aplicada ao tratamento do câncer em cães
}

\section{Oncolytic viroterapy applied to cancer treatment in dogs}

\author{
Jorge Alberto Manso Raimundo da Rocha ${ }^{1 *}{ }^{\mathbb{D}}$; Fernanda Teodoro Rios ${ }^{2}$; \\ Marcello Fiqueredo Campos ${ }^{3}$; Yânca Bizerra Souza ${ }^{4}$ \\ *Autor Correspondente: Jorge Alberto Manso Raimundo da Rocha. Departamento de \\ Fisiologia, Universidade Federal de Sergipe, Av. Desembargador João Bosco de Andrade Lima, 560, \\ apto 603, Bairro Atalaia, Aracaju, Sergipe. E-mail: jamrrocha@yahoo.com.br
}

Como citar: ROCHA, Jorge Alberto Manso Raimundo da; RIOS, Fernanda Teodoro; CAMPOS, Marcello Fiqueredo; SOUZA, Yânca Bizerra. Viroterapia Oncolítica aplicada ao tratamento do câncer em cães. Revista de Educação Continuada em Medicina Veterinária e Zootecnia do CRMV-SP, São Paulo, v.18, n. 3, 2020. Doi: 10.36440/ recmvz.v18i3.38125

Cite as: ROCHA, Jorge Alberto Manso Raimundo da; RIOS, Fernanda Teodoro; CAMPOS, Marcello Fiqueredo; SOUZA, Yânca Bizerra. Oncolitic Virotherapy applied to cancer treatment in dogs. Journal of Continuing Education in Animal Science of CRMV-SP, São Paulo, v.18, n.3, 2020. Doi: 10.36440/recmvz.v18i3.38125

\section{Resumo}

O câncer continua a ser uma das principais causas de mortes em humanos e em cães. Os tumores de ocorrência natural em cães têm muitas similaridades biológicas com os cânceres humanos e respondem similarmente às terapias convencionais. Por isso, pode-se inferir que os protocolos clínicos adotados para os humanos poderiam ser transferidos para o tratamento de cães com câncer e que terapêuticas com êxito no tratamento de tais animais poderiam servir para o tratamento de seres humanos. A viroterapia oncolítica em cães é o objeto deste artigo de revisão.

Palavras-chave: Câncer canino. Vírus oncolíticos. Viroterapia oncolítica.

\section{Abstract}

Cancer remains a leading cause of death in humans and dogs. Naturally occurring tumors in dogs have many biological similarities to human cancers, and respond similarly to conventional therapies. Thus, it can be inferred that human clinical protocols could be transferable for the treatment of dogs with cancer and that successful therapies in the treatment of these animals could be used for the treatment of human beings. Oncolytic virotherapy in dogs is the subject of this review article.

Keywords: Dogs cancer. Oncolytic virus. Virotherapy.

\section{Introdução}

\footnotetext{
1 Professor do Departamento de Fisiologia, Universidade Federal de Sergipe, Aracaju, SE, Brasil 2 Discente da Universidade Federal de Sergipe, Aracaju, SE, Brasil
} 
A despeito dos avanços na Medicina, o câncer continua a ser uma das principais causas de mortes em humanos. 0 tratamento convencional do câncer baseado primariamente em quimioterapia, radioterapia e cirurgia, embora tenha aumentado a taxa de sobrevivência dos pacientes, tem a sua eficácia limitada dependendo do tipo de câncer. O câncer também é uma das principais causas de morte nos cães e apesar da carência de censos, há uma tendência de aumento de mortes por neoplasias nestes animais, em parte devido ao aumento de suas longevidades. Nos cães, os tumores malignos mais comumente diagnosticados são as neoplasias mamárias e os linfomas. Os tumores mamários caninos são os mais frequentes e representam mais de $40 \%$ de todos os tumores das cadelas (GRUNTZIG et al., 2015; CATTANEO et al., 2017).

A ideia de empregar um vírus para eliminar neoplasias surgiu de observações de regressões espontâneas de tumores em pacientes humanos após infecção ou vacinação viral e por mais de 100 anos estes vírus oncolíticos (VOs) vêm sendo pesquisados como agentes experimentais para a cura do câncer. Atualmente estirpes de vírus de pelo menos dez famílias estão sendo empregadas em investigações clínicas para o tratamento do câncer. Os vírus do sarampo (MV), estomatite vesicular (VSV), doença de Newcastle (NDV), herpes simplex (HSV), varíola bovina (VACV), parvovirose (PV), e mixomatose (MYXV) são alguns exemplos de VOs pesquisados na luta contra o câncer em humanos (LAWLER et al., 2017; UNGERECHTS et al., 2016).

\section{Mecanismo de Oncólise}

A progressão de um tumor é um processo dinâmico que envolver mudanças genéticas que desencadeiam um potencial de proliferação sem limite, evasão à apoptose, capacidade aumentada de angiogênese, invasão de tecidos e metástases, e modificação de vias intracelulares de sinalização. As células tumorais apresentam alteração no seu metabolismo energético e possuem instabilidade genômica. A carcinogênese é um processo de muitas etapas, envolvendo a acumulação de anormalidades em genes supressores tumorais, tais como TP53, ATM, RB e RAS, predispondo as células cancerígenas à infecção viral. As células cancerígenas expressam fatores de crescimento tumoral e fatores de crescimento endotelial vascular e também de estimulam a produção de citocinas imunossupressoras que favorecem o estabelecimento d um microambiente tumoral favorável à progressão do câncer e à formação de metástases, pois selecionam clones celulares com imunogenicidade reduzida que escapam à vigilância do sistema imune (SI) do hospedeiro (KAUFMAN et al., 2015; AUBREY et al., 2016; FOUNTZILAS et al., 2017).

Os VOs têm propensão natural para infectar células malignas. Esta preferência deriva de mudanças celulares ocorridas durante a oncogênese tal como na rota de sinalização do interferon (IFN). A expressão alterada de receptores nas células cancerígenas é outro defeito que facilita a infecção viral. Os VOs atacam seletivamente as células cancerígenas produzindo a lise direta das células tumorais e um aumento indireto da imunidade antitumoral do hospedeiro. Por meio destes dois mecanismos principais estes vírus melhoram os resultados da luta contra o câncer. Embora os VOs possam entrar tanto nas células cancerígenas como nas células normais, as primeiras não têm mecanismos contra infeções virais e são incapazes de se defenderem destes vírus. Os mecanismos biológicos usados pelos vírus para matar os tumores dependem de vários fatores, incluindo o vírus, a célula alvo e as rotas biológicas atingidas. Os VOs induzem formas imunogênicas de morte das células tumorais, incluindo apoptose imunogênica, necrose, piroptose e morte de célula autofágica, que ativam as respostas imunes do hospedeiro. Os VOs podem acessar as células ligando-se aos seus receptores de superfície ou pela fusão com a membrana plasmática (BARTEE et al., 2016; FOUNTZILAS et al., 2017; ILYINSKAYA et al., 2018).

Os VOs podem estabelecer o ciclo lítico em células malignas, todavia não em células normais, explorando a fraqueza inerente da célula tumorígena. A seletividade dos VOs pelas células cancerígenas é largamente conferida por aberrações nas rotas de sinalização que 
normalmente bloqueiam a replicação viral. A liberação de antígenos e outros materiais (entre eles, novas partículas virais) das células cancerígenas que morrem, ativam as células dendríticas do sistema imune possibilitando que o câncer seja reconhecido ou "visto" pelo sistema imune que desencadeia a resposta imune contra as células cancerígenas. A terapia viral pode tornar um tumor imunologicamente "frio", não inflamado, em um tumor "quente". A infecção viral do tumor pelos VOs e a inflamação localizada resultante aumentam as funções efetoras das células imunes infiltrantes, revertendo a supressão imune induzida pelo tumor e induzindo a geração de imunidade antitumoral. A liberação de citocinas e quimocinas de células tumorais infectadas e das células T helper infiltrantes altera a balança dos fatores pró- e anti-inflamatórios no microambiente tumoral (TME), provocando uma resposta imune potente contra o câncer (KAUFMAN et al., 2015; LUNDSTROM, 2018).

\section{A Viroterapia Oncolítica}

Os VOs frequentemente eliminam células cancerígenas com o emprego de mecanismos distintos, o que os torna atrativos para o tratamento de pacientes com quadro de recidiva da neoplasia e/ou refratários ao tratamento convencional. O objetivo da imunoterapia com VOs é promover a resposta imune inata e adaptativa para o reconhecimento e ataque das células malignas. Em geral, o estímulo do sistema imune inato provoca respostas imunes mais efetivas, mediadas por linfócitos T e B. Como o desenvolvimento dos vasos sanguíneos é importante no crescimento do tumor, a inibição da angiogênese do tumor representa um esforço importante na terapia do câncer. A destruição aguda da rede vascular do tumor por meio da infecção das células endoteliais associadas ao tumor tem sido obtida com a administração de altas doses de VOs (BARTEE et al., 2016; CATTANEO et al., 2017).

A viroterapia oncolítica (VTO) requer grandes doses de partículas virais, em quantidades superiores as encontradas em vacinas $\left(10^{9}\right.$ versus $\left.10^{3}\right)$, com o propósito de liberação efetiva no sítio do tumor e obtenção de efeitos terapêuticos, porém os anticorpos circulantes pré-existentes podem se ligar aos VOs administrados e retirá-los de circulação, minimizando a penetração viral e diminuindo a eficácia da viroterapia. Este fenômeno é mediado principalmente por anticorpos neutralizantes, pela ativação do sistema complemento, citocinas antivirais, macrófagos e pela saída do vírus da circulação sistêmica para outros tecidos, tais como fígado e baço. Um fármaco imunossupressor como a ciclofosfamida pode ser usado para ampliar o tempo de ação dos VOs. A maioria dos VOs tem eficácia clínica limitada quando usados em monoterapia. A VTO combinada com agentes citotóxicos e/ou radioterapia tem apresentado melhores resultados, sem qualquer toxicidade adicional aparente. Um regime combinatório usando VOs de famílias diferentes pode aumentar sinergicamente a potência oncolítica, evitando respostas imunológicas anti-virais e maximizando as respostas antitumorais. Como a eliminação dos VOs pelo sistema imune do hospedeiro é um grande obstáculo à VTO, a injeção direta de VOs no tumor evita os efeitos inibitórios do TME, induzindo uma resposta imune antitumoral mais exacerbada (FOUNTZILAS et al., 2017; UNGERECHTS et al., 2016).

\section{Viroterapia Oncolítica Aplicada ao Tratamento de Cães}

O desenvolvimento da VTO para pacientes caninos é de suma importância em Medicina Veterinária, entretanto o uso da VTO para o tratamento de cânceres em animais domésticos tem sido limitado e ainda está longe de se tornar comercialmente disponível, em contraste ao progresso atingido com o emprego da VTO em humanos. Vários estudos clínicos estão sendo realizados para avaliar a efetividade de vírus atenuados em cânceres humanos, mas os ensaios em pacientes caninos ainda são raros (GENTSCHEV et al., 2014; BLOMME, 2015; MACNEILL, 2018).

Vários tipos de vírus, nativos ou recombinantes, têm sido testados para a terapia do câncer em 
caninos tais como os adenovírus humano e canino, o vírus da cinomose (CDV), reovírus, o VACV e MYXV (PATIL et al., 2012; GENTSCHEV et al., 2014; HWANG et al., 2013). Vários VOs estão sendo desenvolvidos em testes médico-veterinários com caninos e alguns para uso exclusivo em caninos (URBASIC et al., 2012; ILYINSKAYA et al., 2018).

Os tumores de ocorrência natural em cães apresentam muitas similaridades biológicas com os cânceres humanos e respondem similarmente às terapias convencionais, tendo mais similaridades clínicas com cânceres humanos que quaisquer outros modelos de câncer. Nos cães, as neoplasias que se desenvolvem na maioria das vezes em animais imunocompetentes apresentam recorrência, resistência às drogas e produzem metástases em sítios distantes. A carcinogênese e o comportamento biológico dos tumores em cães têm mais características em comum com humanos que com roedores de laboratório. Os mesmos genes oncogênicos e supressores de tumores contribuem para desenvolvimento de cânceres em humanos e cães (CEKANOVA et al., 2014).

As maiores opções de tratamento disponíveis para cânceres caninos incluem cirurgia, radioterapia, quimioterapia, hipertermia, terapia fotodinâmica e eletroquimioterapia. A despeito do progresso já alcançado no diagnóstico e tratamento do câncer canino avançado, no geral o resultado do tratamento não tem melhorado substancialmente. Assim, o desenvolvimento de novas terapias para o câncer canino avançado é uma alta prioridade e a VTO apresenta-se como uma das mais promissoras terapias para o câncer (PATIL et al., 2012; ILYINSKAYA et al., 2018).

Os médicos-veterinários têm uma oportunidade sem paralelo para desenvolver e avaliar terapias que podem potencialmente beneficiar os seres humanos e as espécies veterinárias. Devido às semelhanças entre as muitas neoplasias dos caninos com a sua contraparte humana, é razoável esperar que os protocolos clínicos humanos venham a ser transferidos para o tratamento dos pacientes animais com câncer e vice versa?? inclusive o uso da VTO (CEKANOVA et al., 2014).

\section{Considerações finais}

Os VOs são relativamente não tóxicos e constituem uma opção de tratamento relativamente barata e efetiva contra vários tipos de cânceres observados nos cães A próxima geração de VO, com melhor seletividade e maior citotoxicidade para tumores, combinados com terapias convencionais, poderá aumentar a contribuição da VTO para enfrentar o câncer nos cães. A VTO pode beneficiar os cães com cânceres e quanto mais VOs forem incluídos em estudos clínicos em humanos, potencialmente mais VTOs se tornarão disponíveis para uso em animais de companhia. Estas terapias devem ser avaliadas em cães com cânceres de surgimento espontâneos para obtenção das informações necessárias sobre a efetividade potencial da VTO para cânceres em humanos e para promover a saúde dos cães (KHANNA et al., 2009; WITHROW et al., 2010; SHOJ et al., 2016).8

\section{Referências}

O AUBREY, B.J.; STRASSER, A.; KELLY, G.L. Tumor-suppressor functions of the TP53 pathway. Cold Spring Harb Perspect Med, v.6, 2016. Disponível em: https://doi.org.br/10.1101/cshperspect.a026062. Acesso em: 28 de jan. 2021.

BARTEE, E.; BARTEE, M.Y.; BOGEN, B. et al. Systemic therapy with oncolytic myxoma virus cures established residual multiple myeloma in mice. Molecular Therapy - Oncolytics, v.3, 2016. Disponível em: https:// doi.org.br/10.1038/mto.2016.32. Acesso em: 28 de jan. 2021.

BLOMME, E.A.G. Veterinary oncology: translating research advances into innovative therapeutic and diagnostic options. The Veterinary Journal, v.205, p. 117-119, 2015. Disponível em: https://doi.org. br/10.1016/j.tvjl.2015.06.005. Acesso em: 28 de jan. 2021. 
CATTANEO, R.; RUSSELL, S.J. How to develop viruses into anticancer weapons. PLoS Pathog, v.13, n.3, 2017. Disponível em: https://doi.org.br/10.1371/journal.ppat.1006190. Acesso em: 28 de jan. 2021.

CEKANOVA, M.; RATHORE, K. Animal models and therapeutic molecular targets of cancer: utility and limitations. Drug Design. Development and Therapy, v.8, p. 911-1922, 2014.

FOUNTZILAS, C.; PATEL, S.; MAHALINGAM, D. Review: oncolytic virotherapy, updates and future directions. Oncotarget, v.8, n.60, p. 102617-102639, 2017. Disponível em: https://doi.org.br/10.18632/ oncotarget.18309. Acesso em: 28 de jan. 2021.

GENTSCHEV, I. et al. Oncolytic virotherapy of canine and feline cancer. Viruses, v.6, p. 2122-2137, 2014. Disponível em: https://doi.org.br/10.3390/v6052122. Acesso em: 28 de jan. 2021.

GRUNTZIG, K.; GRAF, R.; HASSIG, M. et al. The swiss canine cancer registry: a retrospective study on the occurrence of tumours in dogs in Switzerland from 1955 to 2008. Journal of Comparative Pathology, v.152, p.161-71, 2015. Disponível em: https://doi.org/10.1016/j.jcpa.2015.02.005. Acesso em: 28 de jan. 2021.

HWANG, C.C. et al. Oncolytic reovirus in canine mast cell tumor. Plos One, v.8, p.9, 2013. Disponível em: https://doi.org/10.1371/journal.pone.0073555. Acesso em: 28 de jan. 2021.

ILYINSKAYA, G.V.etal. Oncolytic Sendai Virus Therapy of Canine Mast Cell Tumors (A Pilot Study). Frontiers in Veterinary Science, v.5, p. 116, 2018. Disponível em: https://doi.org/10.3389/fvets.2018.00116. Acesso em: 28 de jan. 2021.

KAUFMAN, H.L.; KOHLHAPP, FJ.;ZLOZA, A. Oncolytic viruses: a new class of immunotherapy drugs. Nature Reviews, v, 14, p.642-662, 2015. Disponível em: https://doi.org/10.1038/nrd4663. Acesso em: 28 de jan. 2021.

KHANNA, C.; LONDON, C.; VAIL, D. et al. Guiding the optimal translation of new cancer treatments from canine to human cancer patients. Clinical Cancer Research, v. 15, n. 18, 2009. Disponível em: https:// doi.org/10.1158/1078-0432.CCR-09-0719. Acesso em: 28 de jan. 2021.

LAWLER, S.E.; SPERANZA, M.C.; CHO, C.F. Oncolytic viruses in cancer treatment - a review. JAMA Oncol, v.3, n.6, p.841-849, 2017. Disponível em: https://doi.org/10.1001/jamaoncol.2016.2064. Acesso em: 28 de jan. 2021.

LUNDSTROM, K. New frontiers in oncolytic viruses: optimizing and selecting for virus strains with improved efficacy. Biologics: Targets and Therapy, v.12, p. 43-60, 2018. Disponível em: https://doi. org/10.2147/BTT.S140114. Acesso em: 28 de jan. 2021.

MACNEILL, A.L.; WEISHAAR, K.M.; SÉGUIN, B.; Powers, B.E. Safety of an oncolytic myxoma virus in dogs with soft tissue sarcoma. Viruses, v. 10, p. 398, 2018. Disponível em: https://doi.org/10.3390/ v10080398. Acesso em: 28 de jan. 2021.

PATIL, S.S. et al. Onco-lytic virotherapy in veterinary medicine: current status and future prospects for canine patients. Journal of Translational Medicine, v. 10, p. 3, 2012. Disponível em: https://doi. org/10.1186/1479-5876-10-3. Acesso em: 28 de jan. 2021.

SHOJI, K.; YONEDA, M.; FUJIYUKI, T. et al. Development of new therapy for canine mammary cancer with recombinant measles virus. Molecular Therapy - Oncolytics, v. 3, 2016. Disponível em: https://doi. org/10.1038/mto.2015.22. Acesso em: 28 de jan. 2021.

UNGERECHTS, G.; BOSSOW, S.; LEUCHS, B. et al. Moving oncolytic viruses into the clinic: clinical-grade production, purification and characterization of diverse oncolytic viruses. Molecular Therapy - Methods \& Clinical Development, v.3, 2016. Disponível em: https://doi.org/10.1038/mtm.2016.18. Acesso em: 28 de jan. 2021.

URBASIC, A.S.; STACY HYNES; AMY SOMRAK et al. Oncolysis of canine tumor cells by myxoma virus lacking the serp2 gene. American Journal of Veterinary Research, v.73, p. 1252-1261, 2012. Disponível em: https://doi.org/10.2460/ajvr.73.8.1252. Acesso em: 28 de jan. 2021. 
WITHROW, S.J.; WILKINS, R.M. Cross talk from pets to people: translational osteosarcoma treatments. ILAR Journal, v. 51, p. 3, 2010. Disponível em: https://doi.org/10.1093/ilar.51.3.208. Acesso em: 28 de jan. 2021. 